\title{
Note-taking by nursing students: the case for implementing writing strategies to encourage best practice
}

Taryn Tavener-Smith

\begin{abstract}
Background: Note-taking is an integral component of professional nursing practice. If students are to complete this effectively, a range of teaching, learning and assessment strategies are required to support their development of this skill. Objectives: This study aimed to identify lecturers' perspectives of students' note-taking on placement to identify factors that limit the development of this skill; these perspectives could be used to explore strategies to support students to develop this skill while at university. Design: A qualitative study taking a phenomenological approach was carried out. Participants: Three senior nursing practice visitors agreed to be interviewed. Methods: Semistructured interviews were carried out and thematic analysis carried out to explore lecturers' perspectives of students' experiences of note-taking while on placement. These interviews were intended to obtain detailed accounts of note-taking and allow challenges to be explored. Results: Each participant observed and supported students' note-taking within practice placement settings. Three main themes emerged from the data: limitations to students' vocabulary and literacy; inconsistency between trusts resulting in an inability to articulate experience; and note-taking clarity and accuracy. Conclusion: Note-taking is central to nurses' education and professional documentation to support best practice and high-quality patient care. Variations in processes between trusts, stringency of standards required by the trusts where students attend placements, and students' writing abilities differ widely, which directly affect the consistency and accuracy of written notes.
\end{abstract}

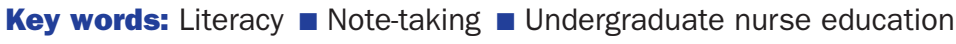
- Vocabulary limitations $\square$ Nursing students

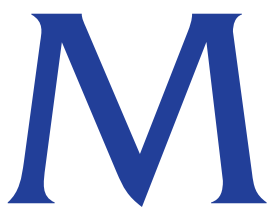

ike Baynham's (2002:188) observation on the writing process demanded of nursing students rings true in contemporary practice: 'Pity the poor nursing student, who is required to write at times like a sociologist, at others like a philosopher, yet again like a scientist and finally as a reflective practitioner!'

Taryn Tavener-Smith, Graduate Teaching Associate, School of Nursing and Allied Health, Buckinghamshire New University, taryn.tavener-smith@bucks.ac.uk

Accepted for publication: August 2020
This realisation provides an appropriate starting point for discussion when considering the role of literacy alongside the practice of note-taking for nursing students on placement. The variety of writing techniques required by universities of their preregistration nursing students presents challenges for supervising nurses, nursing students and nursing lecturers alike regarding how best the development of these skills can be supported.

This study aimed to identify the importance of note-taking for health professionals at work while identifying the factors that make it problematic for nursing students in practice. It also explored some of the considerations that practice visitors (formerly known as link lecturers) (Nursing and Midwifery Council (NMC), 2018a) need to consider when teaching this particular skill.

This study also explored, from the lecturers' perspective, the challenges students face regarding note-taking in practice and identified areas for future research to support pre- and postregistration nursing students with their writing practice to inform their note-taking approaches.

Finally, this study aimed to evaluate the ways in which university lecturers can better prepare nursing students beyond the realm of academic essay writing to accurately and effectively take notes about care activities while on practice placement as part of their degree.

\section{Background}

Note-taking is an essential component of everyday practice for health professionals. This skill is central to ensuring potentially life-threatening or life-saving patient information is documented while establishing continuity of care (Andrews and St Aubyn, 2015: 20). This reasoning is securely established in the adage 'if it's not written down, it didn't happen'; this is ingrained into the minds of practising health professionals and drummed into nursing students during placement.

Should the prospect of nurses' notes being subject to legal scrutiny not be sufficient, the importance of clear and accurate documentation practice is demanded by the NMC Code (2018b), which stipulates that it is necessary to 'prioritise people, practise effectively, preserve safety and promote professionalism and trust'. Codes and maxims such as these underscore both the weight that note-taking carries in nursing practice and the 
sizeable responsibility of those imparting strategies to students to ensure they master the skill.

The role of note-taking within the nursing profession is an integral component of practice (Whitehead, 2002). This skill, acquired and developed throughout a nurse's career, is central to various aspects of professional documentation, including communication between health professionals, documenting treatment plans and processes for standardising and maintaining high-quality healthcare, and establishing a firm paper trail required by law in relation to healthcare procedures (Andrews and St Aubyn, 2015).

Ironically, note-taking is a largely undocumented practice that appears to be overlooked frequently by those in educational roles in terms of directly addressing and teaching this necessary skill (Leki, 2007). Fittingly, Seid and Teklay (2018) acknowledged that there is a "positive relationship between note taking and academic performance'. Such correlations clearly demonstrate the intertwined nature of the two, which underlines the need to address writing skills.

The author carried out an initial literature search on the subject, which identified a gap. There is so little is written about note-taking practice that it is insufficient to promote its role in upholding high-quality care though recording what has happened. Regarding patient handover, to which accurate notes are central, Lee et al $(2015: 160)$ argued that the 'quality of communication at patient handover is inconsistent, compromising patient safety'.

There are two types of note-taking: one involves writing brief notes for handover, based on care-giving activities undertaken during shifts; the other concerns more formal documentation relating to patient records, charts and risk assessments.

This study set out to identify the factors that cause problems in note-taking practices for nursing students. The intention is to implement relevant teaching, learning and assessment strategies to better support students' development of this skill in the future (Johnson et al, 2007).

\section{Ethical considerations}

Ethical approval was granted by the head of the school of nursing and allied health before the study started. Participants were invited to take part in the interviews on an anonymous, voluntary basis and gave consent beforehand. In keeping with confidentiality guidelines outlined by the Data Protection Act 2018, no identifying information was requested from the participants, and none of this information is included in the article.

\section{Method}

\section{Sample}

This study used purposive sampling, with three senior nursing practice visitors selected, one from each nursing field (child,

F adult and mental health) at the school of nursing and allied health at the university. Purposive sampling selects participants based on certain characteristics or experiences (Ellis, 2010).

The participants were selected to represent each of the nursing fields offered by the school. In this way, the researcher was able to ensure 'deliberate choice of a participant due to the qualities the participant possesses' (Etikan et al, 2016: 2). They were carefully selected for the qualities of being senior academics and practice visitors in the school with experience of supervising students' note-taking during placement while also having related teaching responsibilities within the university.

\section{Design}

A qualitative phenomenological approach was selected. Phenomenological research approaches encompass the 'study of the "lived experience"" while providing insight into "what it is actually like to live with a particular condition or experience' (Aveyard and Sharp, 2013: 75).

In this study, the lived experiences encompass practice visitors' observations of nursing students' practice while they were note-taking during a placement. The research design adopted was useful in ascertaining the individual lecturers' experience regarding their observations of note-taking practice.

The research design included semistructured interviews with the three participants. Interview schedules were developed based on the main research questions, which aimed to explore nursing students' experience of note-taking in placement.

The research aim was established as observing nursing students' note-taking during placement while identifying difficulties they experienced in undertaking this. These obstacles were determined in the hope of ascertaining strategies that could better support students regarding the development of this skill in future.

\section{Data collection}

Data were collected using audiorecorded interview. These interviews, conducted by the researcher, were transcribed verbatim so that recurring themes in the data could be identified. Thematic analysis was applied to identify relevant themes (Holloway and Galvin, 2016). Thematic analysis is the method used by qualitative researchers 'for identifying, analyzing, organizing, describing, and reporting themes found within a data set' (Braun and Clarke, 2006: 79). These themes are then applied to the research question. Interview schedules and responses were securely stored throughout the research process to protect confidentiality (NMC, 2018b).

\section{Data analysis}

The interviews were transcribed verbatim to develop transcripts, which were later coded thematically by identifying naturally recurring themes of relevance (Kara, 2017: 68, 178). This data analysis process allowed recurring themes to be identified and addressed and recommendations suggested.

\section{Results}

The participants shared their professional clinical experiences regarding supervising students on placement. Such supervision includes supporting students in note-taking practice to encourage accurate documentation.

The three main themes that emerged from the interviews were: students' vocabulary and literacy limitations; inconsistency between trusts resulting in an inability to articulate experience; and note-taking clarity and accuracy. 
Theme 1. Vocabulary and literacy limitations

Participants identified a disconnect between students' knowledge and what their vocabularies would permit them to communicate in writing while taking notes, resulting in perceived vocabulary and literacy limitations.

Such restrictions pose a challenge for accurate note-taking in practice; this is essential because notes may be called upon later to support decisions pertaining to treatment plans and processes. These restrictions in vocabulary, evidenced in the students' notes, indicate a need for additional support at classroom level to better prepare students to convey their observations:

'It's the general vocabulary ... that is then a stumbling block to their patient notes because, if you haven't got that vocabulary to draw upon, does that actually provide a natural stumbling block to your documentation? Because you can't pull on these words to describe.'

Participant 1

'It's just vocabulary in general ... I noticed that the groups don't know what "thrive" means.

They've never heard of the word "thrive".

Participant 1

'Also, I think there are probably many students who feel they don't have very good writing skills.'

Participant 2

'There are issues of language ... from a university point of view but, more importantly, from a practice point of view.'

\section{Participant 3}

'Overall, the quality of written communication has [been]-is-not as good as it was.'

$$
\text { Participant 3, original emphasis }
$$

\section{Theme 2. Inconsistency between trusts result} in an inability to articulate experience

Participants expressed concerns regarding nursing students' seeming inability to accurately and coherently capture and express, through note-taking, care activities that had been carried out.

Examples included: an inability to write effective notes while working in high-pressured environments; lacking the necessary vocabulary to precisely articulate processes; and difficulties in producing notes that were straightforward or clear so that they could be understood at the end of each shift.

These limitations were largely a result of little consistency between approaches to written records and note-taking at different trust placements, and these limitations were also observed in the students' academic writing. Such inconsistencies were problematic, given that well-rounded, detailed accounts should be captured in patient notes regarding treatments and observations:
'I think just being literal, like actually being able to describe how you got from A to B ... being able to have that ability to break things down into chunks [is lacking].'

Participant 1

'Our students go to so many different trusts, so many trusts, even the child students go to multiple trusts. And each trust has its own paperwork. And if you think, as a student, you're in somewhere for 6 weeks and you nail their paperwork, then you go to another ward, completely different paperwork again ...

Any bit of confidence they have built up is just being diminished.'

Participant 2

'[There are] differences [in note-taking strategies] between community settings and inpatient settings.'

Participant 3

\section{Theme 3. Note-taking clarity and accuracy}

Participants emphasised the importance of clarity in student nurses' note-taking for documentation and central communication between health professionals. The skill of providing clear medical notes appeared to be a unanimous point of concern and requires attention:

'I think that we drill it into the student nurses right from week 1 of their training that ... the clarity of their patient notes has to be that clear that someone off the street can come in who's not a nurse, read their notes and completely understand, step for step, very transparently, the care that they've provided.'

Participant 1

'I'm saying to students: if there's something important and that happened now, take the time to sort, you know, to write it down now, to make note of it now.'

Participant 2, original emphasis

'In terms of accuracy ... students can give you the general gist but, if you ask about something more detailed, they don't always remember.'

Participant 2

'Academically, you need to improve the clarity of your writing. But the main reason, from my perspective, for you doing that is because the clarity of your writing has to improve and has to be good in practice. Because if you're not communicating clearly, you know, ultimately that's life or death stuff.'

Participant 3 


\section{Discussion}

The issues raised by participants suggest that many nursing students struggle with note-taking while on placement. Problems include: limitations to students' vocabulary and literacy; inconsistency between trusts resulting in an inability to articulate experiences; and note-taking clarity and accuracy.

The obstacles students face in relation to note-taking appear to have more to do with underdeveloped skills than extraneous factors such as fatigue, the time constraints of working on a busy ward, and lacking an understanding of the importance of this practice in health care, although these are considered to be contributing factors (Guhde, 2003; Choi, 2005; Salamonson et al, 2008).

These findings, based on practice visitor observations and experience, indicate a clear need to support students both in the classroom from a theoretical perspective and in practice to enhance their vocabulary, clarity, and accuracy when writing.

Limitations in the existing literature are evident and further research on the subject is required.

\section{Limitations}

While raising some interesting issues regarding nursing students' note-taking strategies and challenges in practice, this study has limitations that require attention.

One is its small scale, which restricts its ability to be applied to the general student population. As a result, caution should be practised when attempting to generalise these findings because they may not be representative of the wider population.

In addition, this study presents the professional perspectives of three lecturers and so may not necessarily represent the student's personal experiences of note-taking while on placement. Future studies would do well to explore note-taking from the student's perspective to identify the challenges they experience. Such expansions to this study would undoubtedly yield valuable insights while capturing the nursing student's perspective.

Given the overarching limitations in the current literature, it was important to ascertain extensive detail by relating the perspective of people who have experienced a particular phenomenon (Aveyard and Sharp, 2013; Paley, 2016; Lin, 2017). In this instance, these expert insights were obtained from senior lecturers with practice and academic experience.

\section{Conclusion}

Overall, nursing students' note-taking is a nuanced issue with numerous layers of challenge for all stakeholders, including students learning to write notes, lecturers supporting the writing process and practice assessors guiding students while they are on placement (the terms practice supervisor, practice assessor and academic assessor are replacing the terms mentors and sign-off mentors (NMC, 2018a).

Observable obstacles include: limitations to students' vocabulary and literacy; inconsistency between trusts resulting in inability to articulate experience; and note-taking clarity and accuracy.

This study explored the challenges students face from the lecturers' perspective of note-taking in practice and identified

\section{KEY POINTS}

Note-taking is an essential part of nursing practice because it is central to ensuring that patient information is accurately documented

- Consistency in note-taking is imperative to ensure continuity of care

- Note-taking is a nuanced issue involving numerous layers of challenge for all stakeholders

- Limitations in students' vocabulary and literacy impact their note-taking ability

- Variations in trusts' documentation processes prove problematic for nursing students attempting to master note-taking

- Writing strategies within formal education are needed to support the development of students' note-taking skills

some considerations for future research to support pre- and postregistration nursing students with their writing practice to inform their note-taking approaches.

\section{Recommendations}

Further research is required regarding the issue of nursing students' note-taking in practice to gain more insight into the reasons why this aspect of training is lacking in formal teaching within nursing programmes.

Further research could take the form of a mixed-method study including a wide variety of students to cover the representative population of nursing students, which would provide a generalisable overview of current obstacles.

It is important that processes to encourage nursing students' development of this skill are relevant and are updated to improve active engagement both inside and outside the classroom for all stakeholders such as students, trusts, lecturers and facilitators.

In terms of classroom-based support, it is essential that more formal learning-focused activities are implemented to ensure more well-rounded support for nursing students' development of these skills. While such learning practices are undertaken on wards where nursing students are on placement, more conscious efforts are required on behalf of all stakeholders to ensure that shortfalls are actively addressed to improve documentation in healthcare settings.

Possible strategies to support students include simulated note-taking exercises, alongside dedicated initiatives to develop vocabulary. These approaches align closely with the NMC (2018a) standards, which emphasise requirements for practice learning,where both practice supervisors and assessors share the responsibility of supporting students in the development of their practice vocabulary and documentation skills.

Finally, this study has explored lecturers' perspectives regarding nursing students' note-taking abilities. As such, the knowledge base on this subject would benefit from including students' perspectives alongside those held by practice supervisors and assessors. Obtaining a student-centred perspective on the experience of note-taking would, ultimately, help to ensure that a multidimensional view is gained of the issues surrounding this practice for students in placement. BJN

\section{Declaration of interest: none}


Acknowledgement: this research was supported by the School of Nursing and Allied Health at Buckinghamshire New University

Andrews A, St Aubyn B. If it's not written down, it didn't happen. J Community Nurs. 2015;29(5):20-23

Aveyard H, Sharp P. A beginner's guide to evidence-based practice in health and social care. 2nd edn. Maidenhead: McGraw-Hill/Open University Press; 2013

Baynham M.Academic writing in new and emerging discipline areas. In: Harrison R, Reeve F, Hanson A, Clarke J (eds). Supporting lifelong learning. Volume 1. Perspectives on learning. 1. London: RoutledgeFalmer; 2002

Braun V, Clarke V. Using thematic analysis in psychology. Qual Res Psychol. 2006;3(2):77-101. https://doi.org/10.1191/1478088706qp063oa

Choi LLS. Literature review: issues surrounding education of English-as-asecond language (ESL) nursing students. J Transcult Nurs. 2005;16(3): 263-268. https://doi.org/10.1177/1043659605274966

Ellis P. Understanding research for nursing students. 1st edn. Exeter: Learning Matters; 2010

Etikan I, Musa SA, Alkassim RS. Comparison of convenience sampling and purposive sampling. Am J Theor Appl Stat. 2016;5(1):1-4. https://doi. org/10.11648/j.ajtas.20160501.11

\section{CPD reflective questions}

- Describe some of the challenges students face while learning how to take notes in practice and identify factors that may impede good note-taking

- Consider students' note-taking proficiency. Do you feel confident in assessing their abilities?

- If you identified students who require additional support to help improve their note-taking, would you know where you could refer them?
Guhde JA. English-as-a-second language (ESL) nursing students: strategies for building verbal and written language skills. J Cult Divers. 2003;10(4):113-117

Holloway I, Galvin K. Qualitative research in nursing and healthcare. Oxford: Wiley Blackwell; 2016

Johnson MK, Symes L, Bernard L, Landson MJ, Carroll TL. Mentoring disadvantaged nursing students through technical writing workshops. Nurse Educ. 2007;32(4):168-172. https://doi.org/10.1097/01. NNE.0000281087.43088.f5

Kara H. Research and evaluation for busy students and practitioners: a time-saving guide. 2nd edn. Bristol: Policy Press; 2017. https://doi. org/10.2307/j.ctt1t89fsw

Lee H, Cumin D, Devcich DA, Boyd M. Expressing concern and writing it down: an experimental study investigating transfer of information at nursing handover. J Adv Nurs. 2015;71(1):160-168. https://doi. org/10.1111/jan.12484

Leki I. Undergraduates in a second language: challenges and complexities of academic literacy development. London: Routledge; 2007

Lin CS. Revealing the 'essence' of things: using phenomenology in LIS research. Qual Quant Methods Libr. 2017;2(4):469-478

Nursing and Midwifery Council. Realising professionalism: standards for education and training. Part 2 Standards for student supervision and assessment. London: NMC; 2018a. https://tinyurl.com/y8ws3y7c (accessed 20 January 2020)

Nursing and Midwifery Council. The code: professional standards of practice and behaviour for nurses and midwives. London: NMC; $2018 \mathrm{~b}$

Paley J. Phenomenology as qualitative research: a critical analysis of meaning attribution. London: Routledge; 2016. https://doi. org/10.4324/9781315623979

Salamonson Y, Everett B, Koch J, Andrew S, Davidson PM. English-language acculturation predicts academic performance in nursing students who speak English as a second language. Res Nurs Health. 2008;31(1):86-94. https://doi.org/10.1002/nur.20224

Seid A, Teklay H. Training improved the note taking skill of nursing students in Aksum University; northern Ethiopia: a classroom-based action research. BMC Res Notes. 2018;11(1):543. https://doi.org/10.1186/s13104-018-3614-0

Whitehead D. The academic writing experiences of a group of student nurses: a phenomenological study. J Adv Nurs. 2002;38(5):498-506. https://doi. org/10.1046/j.1365-2648.2002.02211.x

\section{Helping nurses treat common skin conditions}

This practical and user-friendly book is made up of articles from a popular series in Practice Nursing and covers:

- The aetiology, diagnosis, management and prevention of most common dermatological cases

- Social and psychological factors and their impact on patients and treatment of skin conditions

It has been highly illustrated with colour pictures provided throughout to aid diagnosis. The chapters have been presented in a user-friendly format making this a highly practical text for nurses and GPs.

ISBN-13: 978-1-85642-401-1; 297 × 210 mm; paperback; 200 pages; publication 2010; £29.99

'Dermatology Differential Diagnosis has a very user-friendly format making it easy to read and select the relevant information required. It has a very practical, hands-on feel, providing the reader with accurate, concise information regarding the aetiology, diagnosis, management and prevention of the skin conditions featured in the text.'

Liz Williams, Nurse practitioner/independent prescriber, Practice Nursing

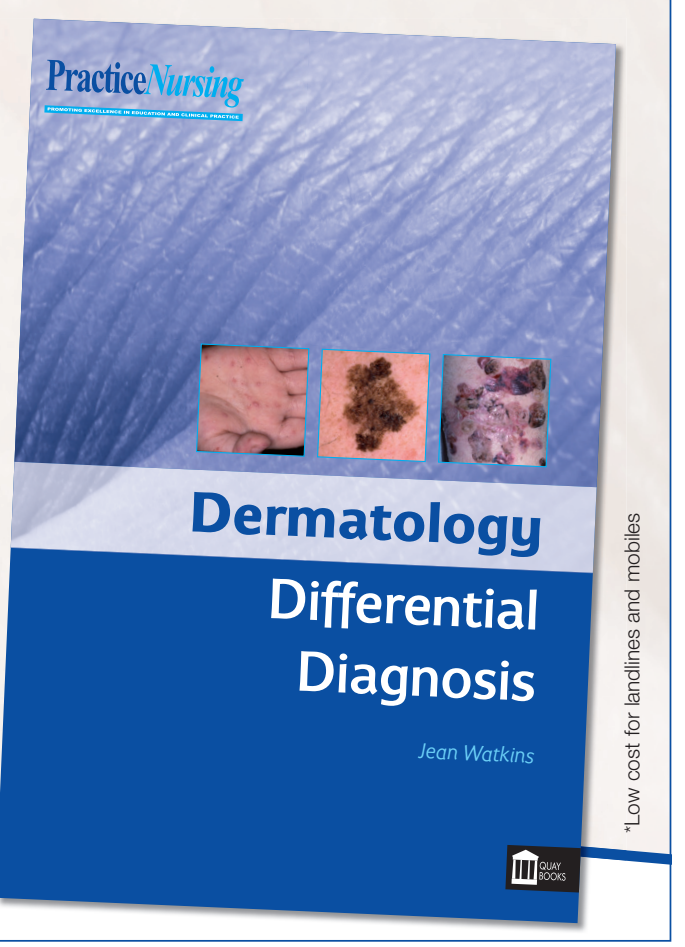

Order your copies by visiting or call www.quaybooks.co.uk +44 (0) 333800 1900* 